\title{
Founding a systems research network for rice
}

\author{
H.F.M. TEN BERGE ${ }^{1}$ and M.J. KROPFF ${ }^{1,2}$ \\ ${ }^{1}$ Research Institute for Agrobiology and Soil Fertility (AB-DLO), P.O. Box 14, 6700 AA \\ Wageningen, The Netherlands; ${ }^{2}$ International Rice Research Institute (IRRI), P.O. Box 933, \\ Manila, The Philippines
}

Key words: capacity building, NARC, research network, rice, simulation, SARP, systems analysis, training

\begin{abstract}
A systems research network for rice was established in eight Asian countries with 15 national agricultural research centres (NARCs) via the SARP project. NARCs are participating with interdisciplinary teams. A 'team establishment phase' covered six years, and included three international training programs. It was followed by an 'application phase', currently addressing six 'application pograms'. Mechanisms used in capacity building after the formal training phase are case studies, team visits by project staff, joint research planning and output analysis, short ( 3 months) and long ( 1 year) fellowships for exchange visits of team members, annual thematic workshops; $\cdot \mathrm{PhD}$ fellowships, support to local (national) training courses, a proceedings series for project publications, and the development and distribution of user friendly shells to facilitate the use of simulation models. Joint research programs were headed by 'theme coordinators'. The paper presents three examples of eco-regional analyses: (I) on the optimization of nitrogen use in rice; (II) on the effects of climate change on rice production; and (III) on agroecological zonation. It is concluded that systems research networks can provide a solid basis for a range of eco-regional studies on various topics, and for local in-depth studies.
\end{abstract}

\section{Eco-regional analysis and systems research networks}

The delineation and characterization of eco-regions is useful for targeting application domains of production technologies and development policies. It is also seen, now, as one of the first steps required in the process of research prioritization for agricultural development, because it is the basis of ex-ante assessment of the possible impacts (and their geographic extent) of changes in technology or in the socio-economic environment. Such assessments may be of explorative or predictive nature and are, of course, only possible after properly expressing the relevant production systems in the form of accepted models and their corresponding quantified parameters. Systems analysis both in its model development and application phases - is therefore an indispensible element in the eco-regional approach to development research.

Constructing models for eco-regional analysis is team work. Good models enable the extrapolation of localized research findings across the eco-region, they may give guidance to local in-depth research, and should not require excessive data inputs. Workable models are a practical blend of empirical 
and explanatory formulations, and their shape varies with their purpose. To arrive at models that are acceptable to a sufficiently broad users group for the purpose of eco-regional analysis, it is not only necessary to piece together different 'disciplinary insights' in a balanced manner, but also to cover - in the developing and testing procedures - the range of locations representative of conditions across the entire eco-region. This leads to the conclusion that, already during the model development process, scientists from various disciplines and at various sites need to be involved in order to arrive at reliable products. Research networks enable the necessary development of a common language of concepts, models and data bases, and allow frequent interaction among actors. Networks are thus a logical format to execute the tasks of development, testing and application of models for eco-regional studies.

A systems research network has been established in the Asian rice producing countries through the SARP (Simulation and Systems Analysis for Rice Production) project. Extensive descriptions of the project have been given earlier (Ten Berge 1993; Kropff et al. 1994). This paper presents an overview and discusses the main project features in retrospect. It also includes summaries of three cases of eco-regional work, executed within the framework of SARP.

\section{The SARP project and its development phases}

SARP is a collaborative project among agricultural research centres. It involves a number of national agricultural research centres (NARCs) in the Asian region, the International Rice Research Institute (IRRI), the DLO Research Institute for Agrobiology and Soil Fertility (AB-DLO, formerly $\mathrm{CABO}$ ), and the Department of Theoretical Production Ecology of the Wageningen Agricultural University (TPE-WAU). Among the participating NARCs are a number of universities. The NARCs altogether represent eight countries: India, China, Bangladesh, Korea, Thailand, Malaysia, Indonesia and The Philippines. The locations of the centres are depicted in figure 1, the corresponding acronyms are given in list of acronyms. Each of the centres is represented by an interdisciplinary team of scientists.

While the longer term objective of the project is to improve sustainable productivity of rice based systems, the immediate goal is to build research capacity in systems analysis and crop simulation. Three phases are distinguished from an administrative viewpoint: Phase I (1984-1987), Phase II (1988-1991), and Phase III (1992-1995). During the first two phases, the international training programs were the core of project activities. Three consecutive groups of scientists were trained during the 1986-1987, 1988-1989 and 1990-1991 international training programs. A total of 91 NARCs based scientists received the formal training. Their disciplinary backgrounds are listed in table 1 . 


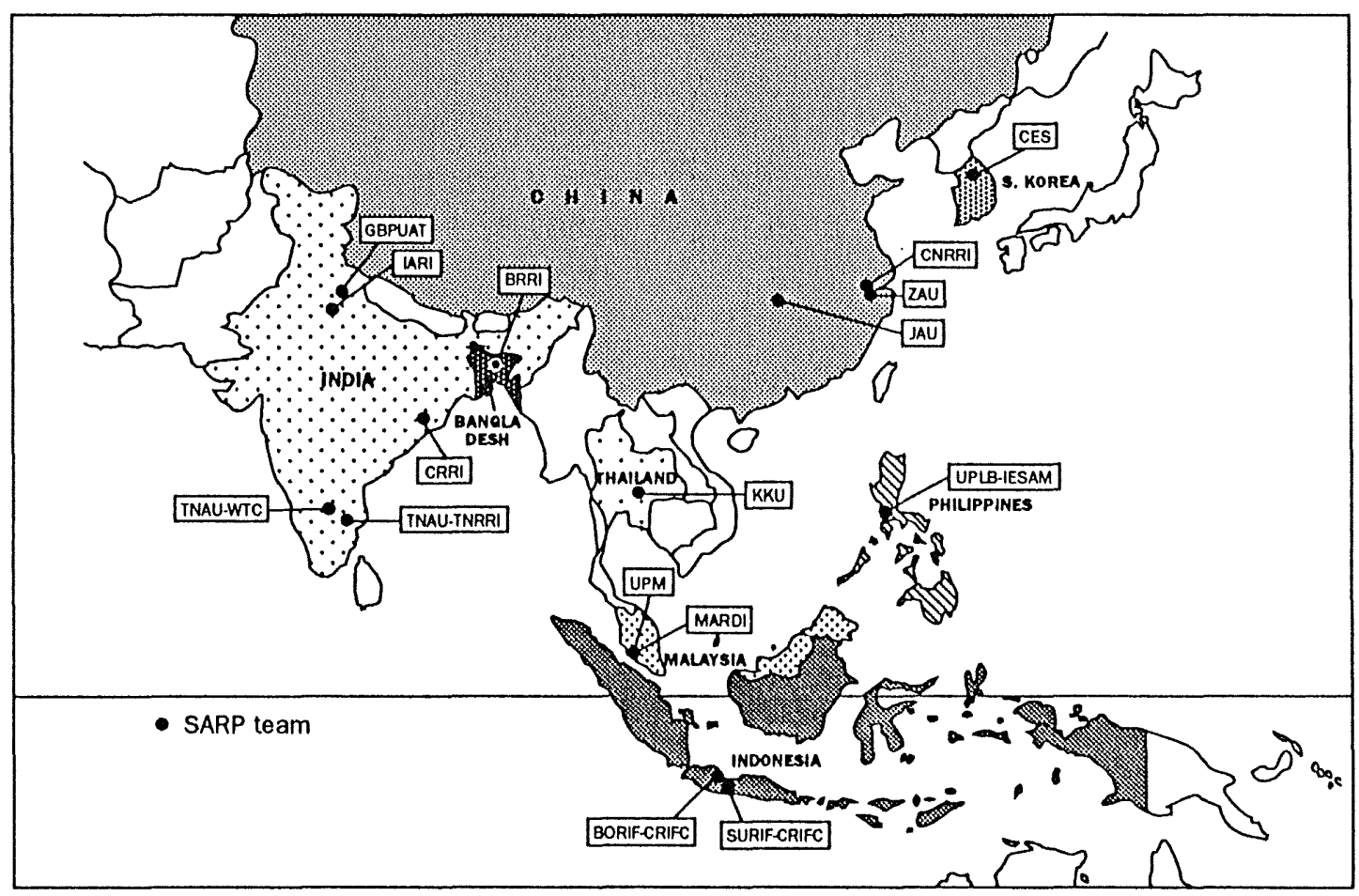

Fig. 1. Countries and NARCs participating in the SARP project. Only primary teams are indicated. (Secondary teams were established via in-country training programs).

Table 1. Number of scientists that received SARP training, per year, and discipline.

\begin{tabular}{lcccc}
\hline & $1986-1987$ & $1988-1989$ & $1990-1991$ & Total \\
\hline Agronomy & 8 & 4 & 5 & 17 \\
Plant/crop physiology & 3 & 7 & 4 & 14 \\
Entomology & 5 & 3 & 5 & 13 \\
Plant breeding & 2 & 4 & 2 & 8 \\
Soil chemistry/fertility & 3 & 4 & 1 & 8 \\
Plant pathology & 3 & 1 & 3 & 7 \\
Soil physics & 2 & 2 & 4 & 8 \\
Statistics/computer & 3 & - & 3 & 6 \\
(Micro)meteorology & 2 & 1 & 1 & 4 \\
Forestry & - & - & 1 & 1 \\
Irrigation/water management & - & - & 1 & 1 \\
Food engineering/aquaculture & - & - & 1 & 1 \\
Weed science & - & - & 1 & 1 \\
Horticulture & - & - & 1 & 1 \\
Nematology & 1 & - & - & 1 \\
Total & 32 & 26 & 33 & 91 \\
\hline
\end{tabular}


Building upon case studies initiated as part of the training programs, activities gradually transformed during Phase II into a collaborative international research program. Phase III aims at further developing this research program, thereby simultaneously consolidating the established systems research capacity in the form of a research network, and elaborating applied research issues towards tangible outputs. Thus, alternative to the formal Phases I-III, the project's history can be divided into a 'team establishment phase' (up to 1990) and an 'application phase' (from 1990 onward). This distinction is maintained in the following, although developments were obviously not identical at all centres, nor did occur simultaneously.

\section{Key elements of the team establishment phase}

\section{Institutional aspects}

NARCs were asked to establish small teams (originally 4 members) to participate in the training program. A prerequisite for participation of NARCs in SARP was that their team would be enabled to continue to work as a unit, and that they would be full time available to systems research work, at least for the duration of the one-year training program. Participation requirements for individuals were a good command of the English language, and some research experience preferably equivalent to $\mathrm{MSc}$ or $\mathrm{PhD}$ level. Teams were usually grouped around an agronomist, plant breeder or crop physiologist, and included scientists from other disciplines such as soil science, agrometeorology, entomology and phytopathology. Two groups of teams were established via the first two international programs (1986-1987 and 1988-1989). The last training program (1990-1991) was used to reinforce these teams, rather than admitting new centres to the network.

Each team was headed by a team leader, responsible for contacts with SARP staff and for integrating research plans. A senior scientist from each centre was assigned as team supervisor, whose main task was to help develop case studies in line with institute research priorities, and to support team activities at the home base by assuring access to research facilities.

Case studies undertaken by teams were directly derived from the institute's current research agenda, thus ensuring a continued interest also after the training phase.

Hardware was donated to each centre for easy access by all team members, and one team member was responsible for maintenance. At a later stage, with the popularization of personal computers, hardware became less of a constraint, although it still is in some centres. The maintenance of models and other software, on the other hand, has gradually become more problematic, one of the causes being the - encouraged - free proliferation of models and modules. 


\section{Training aspects}

The goal of the training phase was to transfer the skills of model building, not to teach the use of particular models. Where existing models were used, they were fully open and were explained line by line. They served as an example or starting point for further elaboration, and their source codes were freely available. This philosophy proved useful for most participants. Younger participants, however, generally felt more at ease developing programming skills than the more senior scientists.

The training program consisted of three sections: the formal course (originally eight, later six weeks), the case study, conducted at the home institute, and a study workshop, after roughly eight months, to report results of the cases studies. During the formal course, participants were guided through all steps from word processing, the use of operating systems, principles of modelling, simulation languages, to model building and evaluation. The scientific contents covered the principles of potential production (crop physiology, agrometeorology), water limited production (soil physics, plant-water relations), nutrient limited production (plant-nitrogen relations; 3-quadrant analysis), and yield reducing factors (crop-pest interactions; principles of population dynamics). All participants attended the entire program, irrespective of their disciplinary background. To some extent this was seen as an advantage, enabling more cross-disciplinary interactions among team members. Many participants, however, felt that a flash course across so wide a range of topics was too much, and in later national courses, organized by NARCs themselves, course contents were much reduced.

One or more case studies on a given rice cropping system were formulated by each team at the conclusion of the training course. Bottlenecks within the system were analyzed, for example problems related to transplanting, timing, and the choice of pre-and post rice crops. In some cases, especially in the field of rice pests, more discipline-oriented cases were formulated and conducted. Case studies initially emphasized the development of simulation skills, but later included experimental work to develop, test and validate models.

Teams were visited by SARP staff during the execution of the case studies. The duration of these visits was one to two weeks per team during the establishment phase. The main purpose was to provide direct hands-on support to the team's simulation activities and to interact with the team supervisor and institute's management. Lateron, team visits were shorter and more devoted to the planning, execution, and analysis of field experiments. 


\section{Key elements of the application phase}

\section{Scientific organization}

While emphasis in the first SARP years was more on developing modelling skills, participants developed a stronger interest in combining experimental and modelling work during the early application phase. This allowed the improvement of model quality and broadening of application ranges. Socalled 'common experiments' became the basis for coordinated network-wide joint experimentation. More recently a return to 'desk activity' was observed, associated with the compilation and analysis of vast sets of collected data in view of the project's ending.

To attain more focus in research efforts, 'research themes' were formalized in 1990. Workshops became centred around these themes: agro-ecosytems; potential production; water, nutrients and roots; and pests, diseases and weeds. Although SARP staff at IRRI and in AB-DLO/TPE-WAU were not assigned to particular themes, their activities gradually differentiated too. This was institutionalized with the start of the third project phase in 1992. From then on, a 'theme coordinator' was assigned to each of the four research themes, to support the research activities at the NARCs. Two coordinators were based at IRRI, and two at AB-DLO/TPE-WAU. An additional task of the coordinators was to address gaps in the understanding of rice production systems and in the models, by conducting their own research. They played a central role in developing various types of specialized software, e.g. models, data entry sheets, and 'user shells'. The two IRRI based coordinators took a relatively large share of logistic support to the project - including the organization of workshops and the editing of the SARP newsletter - in addition to their scientific work.

The coordinators were, and still are, supported by so-called 'theme leaders', senior scientists at IRRI and AB-DLO/TPE-WAU providing scientific guidance in research planning. While the costs of coordinator positions were borne entirely by the project, time inputs by the theme leaders were core inputs from IRRI, AB-DLO and WAU-TPE.

The differentiation of research has been instrumental in providing a better structured support to thematic activities. It counteracted however, to some extent, the interdisciplinary work originally envisaged. Another drawback was that coordinators found it increasingly difficult to support all team activities during their visits. The role of workshops became therefore more prominent.

While a relatively broad structure of four themes was sufficient upto 1993 , research activities are now (1994 onward) grouped into six so-called 'application programs', to strengthen the focus on practical research in the network. These programs are: 
a. Agro-ecological zonation and characterization

b. Optimization of crop rotation and water use

c. Application of models in plant breeding programs

d. Evaluation of climate change impact on rice production

e. Optimization of nitrogen management

f. Optimization of pest management

Much of the work conducted in these application programs can be classified as 'eco-regional', in the sense that it builds on a common scientific basis integrating 'eco-region wide' contributions from many scientists, and using models and approaches that were co-developed and tested across the wide range of conditions found in the major rice production areas of south, southeast and east Asia. Characteristic is, in our view, the mutual (cross-locational) enhancement of research efforts, through common model development, common experimentation and model parametrization, and the development and application of common methodologies in data selection and analysis. Some results of three such eco-regional application programs are presented in the following paragraphs.

\section{Case I. Improved nitrogen management}

This program aims at improving nitrogen management in rice, by developing tools for generating localized recommendations. Optimization of nitrogen (N) management in rice is high on the list of priorities of all research centres participating in SARP. While $\mathrm{N}$-fertilizer recommendations are still mostly issued as 'blanket recommendations', it is recognized that substantial gains can be made by site tailored management. This requires a general description of the key processes, combined with site specific parameter values. Suitable procedures must be designed such that model inputs can easily be derived from field experiments at research stations.

A series of three 'common experiments' was conducted during 1990-1994 (Ten Berge et al. 1994). These experiments were directed at three key processes: fertilizer $\mathrm{N}$ recovery, crop $\mathrm{N}$ uptake capacity, and utilization of $\mathrm{N}$ after absorption by the crop. Teams in India (TNAU-TNRRI, SWMRI, CRRI), China (ZAU, JAU), Korea (CES), Indonesia (BORIF, SURIF), Malaysia (UPM, MARDI), and The Philippines (IRRI) participated in various phases of the experiments. This resulted in the formulation of a simple model, based on empirical soil and crop parameters. Soil parameters are the native soil $\mathrm{N}$ supply rate, directly estimated from $\mathrm{N}$ uptake in non-fertilized plots, and the fertilizer $\mathrm{N}$ recovery $v s$. time after transplanting. The crop parameters are maximum $\mathrm{N}$ uptake rates (relative to growth; and as an absolute rate), maximum crop $\mathrm{N}$ concentration, grain $\mathrm{N}$ content, and an empirical calibration factor (FSV) expressing the efficiency at which radiation and leaf nitrogen are used. After parametrization for a given combination of site, variety and 
270

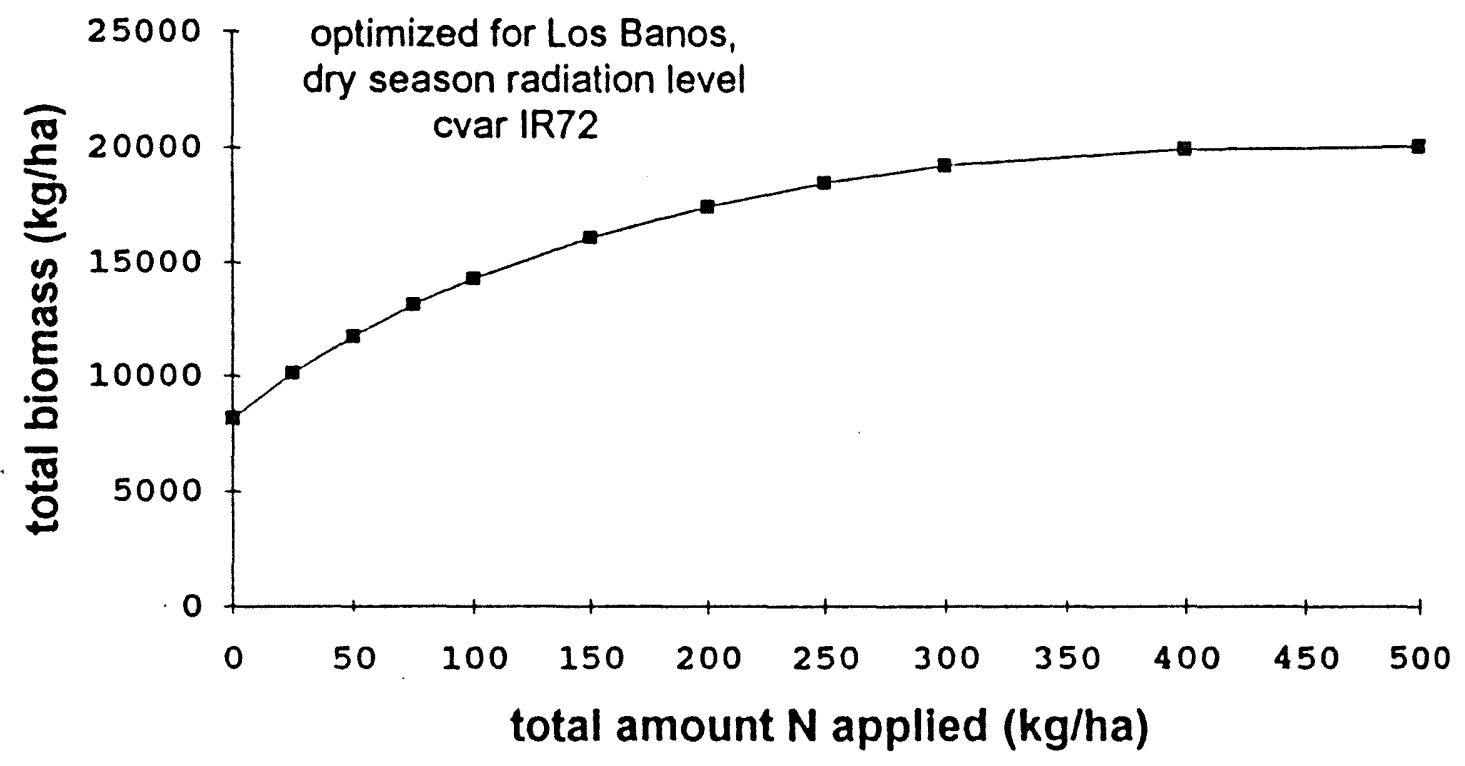

Fig. 2. Maximum attainable crop biomass for cultivar IR72 at selected total $\mathrm{N}$ input levels, for dry season conditions at Los Baffos (Philippines), as generated by MANAGE-N.

weather conditions, the model is run with an optimization procedure which generates a 'best attainable' $\mathrm{N}$ response curve, and the optimal timing of fertilizer dressing for each $\mathrm{N}$-application level (figures 2 and 3). Some conclusions:

- The efficiency factor FSV often steeply decreases after flowering. This was found frequently at two sites in India and in China, but not in The Philippines.

- Wet season efficiencies are lower than dry season values under Indian conditions, while the reverse is true at the IRRI farm.

- At several locations the $\mathrm{N}$ uptake capacity is strongly reduced from first flowering onward - or even earlier, as in some soils of West Java.

Although these contrasts are not fully understood, the observations can be used to derive numerically optimized local $\mathrm{N}$ management recommendations. A number of SARP teams are now comparing computer based recommendations with current 'standard' recommended practices. It was concluded from these comparisons that, in sufficiently fertile soils, basal $\mathrm{N}$ application should be reduced or entirely skipped and saved for later application, to increase yields at the same input level. So far, basal application has been widely recommended.

The package is now polished and wrapped as a user-friendly tool (MANAGE-N), for use by non-modellers at experiment stations. A further step could be to involve extension workers. Tamil Nadu Rice Research Institute has organized a course for scientists from 10 substations, guiding them in collecting the relevant data and using the software to generate specific rec- 


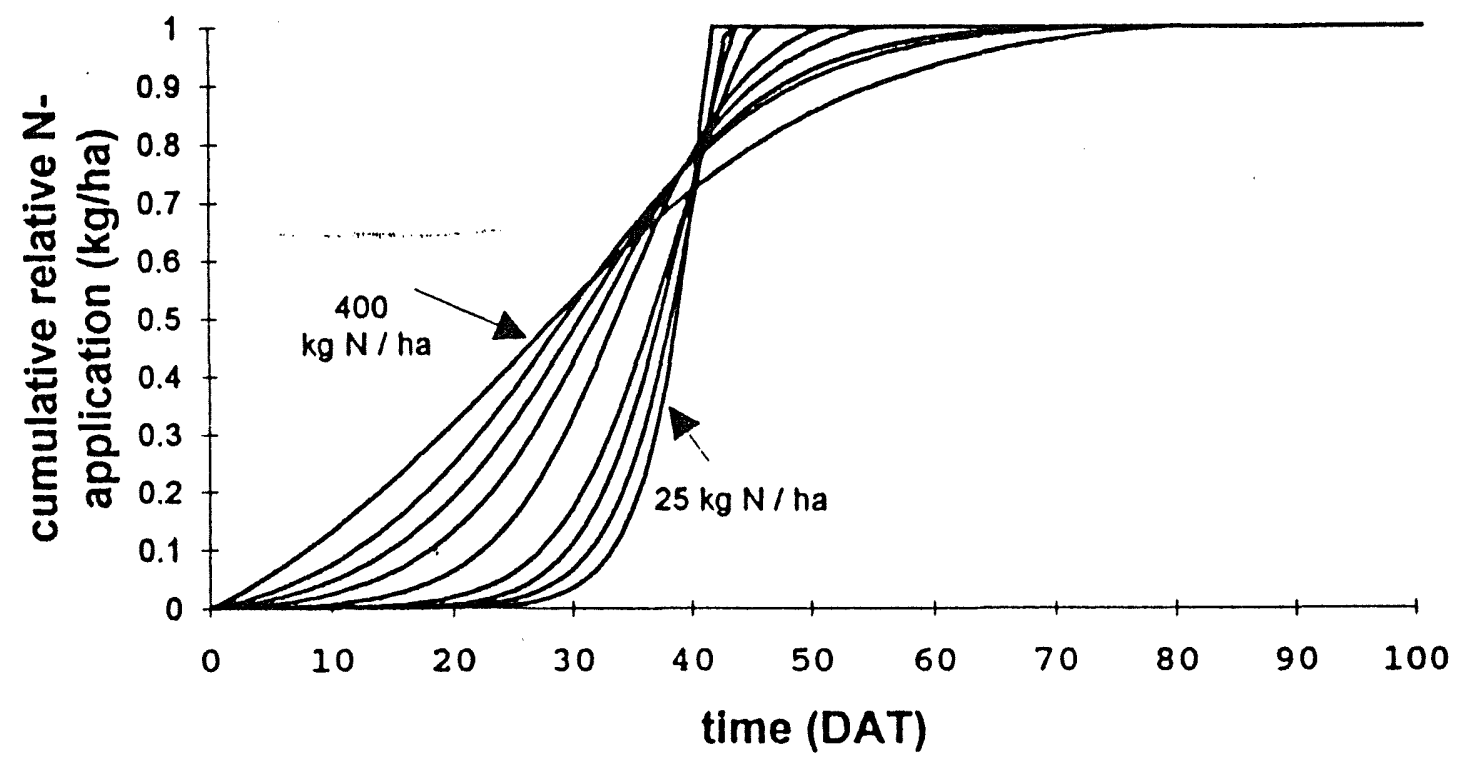

Fig. 3. Nitrogen fertilizer recommendation curves for maximum biomass production in rice cultivar IR72, for dry season conditions at Los Baños (Philippines), as generated by MANAGE-N.

ommendations. Large inter-site contrasts are found in this region, notably with respect to soil $\mathrm{N}$ supply and pest-N interactions. MANAGE-N will be further developed to allow the assessment of management options in contingency situations, i.e. for aged seedlings, after flood damage, and to evaluate the consequences of withholding further $\mathrm{N}$ dressings when pests occur.

\section{Case II. Impacts of climate change on rice production}

This program is centred around the Asia-wide evaluation of the effects of climate change on rice production. These have been studied by four SARP teams within the context of a larger IRRI-EPA collaborative project (Matthews $e t$ al. 1994). Research teams from Korea (CES), Malaysia (UPM), China (CNRRI) and India (TNAU-TNRRI) participated in the simulation studies, evaluating the effects of increased temperatures and doubled $\mathrm{CO}_{2}$ concentrations. One aspect of the simulation models that needed refinement for this study was the relation between temperature extremes and spikelet formation and sterility. The results obtained at all sites have benefited from the regional approach, mobilizing expertise in this specialized field.

Common elements, apart from the use of common models, were the joint collection of weather data, varietal parametrization, and the use of common climate change scenarios. The latter were obtained from the General Fluid Dynamics Laboratory (GFDL), the Goddard Institute of Space Studies (GISS), and the United Kingdom Meteorological Office (UKMO), and were generated for the entire Asian rice region with the help of general circulation models. These models predicted a rise in temperature in all major rice zones, 
and increased precipitation in $60 \%$ of the area. $\mathrm{CO}_{2}$ levels were assumed to either double or remain constant.

Rice responses to these changes were simulated with the help of the SIMRIW and ORYZA-1 models. Both models simulate the development and potential growth of rice in relation to temperature, solar radiation and varietal characteristics. Crop models can quantify the trade-off between yield decrease, arising from the predicted warming, and yield increase due to increased $\mathrm{CO}_{2}$ levels. The uncertainty in these evaluations is mainly associated with uncertainties about the climate shifts which are used as inputs. Yield declines were predicted under all scenarios for Thailand, Bangladesh, and South East China, while increases were predicted for Malaysia, Indonesia and western India (table 2). The overall production in the region changed by $-12 \%$ to $+7 \%$, depending on the climate model used. For the Philippines, wet season yields would increase, but dry season yields would decline in some regions and rise in others.

Overall rice production in China would decline, notably in south-east China, although there was a considerable differentiation between early and late rice seasons. Korean rice yields would generally increase. In Japan, net production changes were predicted to be negligible, although the geographic distribution would change, the northern areas benefiting from longer growing season and reduced cold damage, the south suffering from the damaging effects of high summer temperatures on spikelet fertility.

The study points at the importance of breeding efforts towards higher temperature tolerance during flowering. The gains of such investments can be quantified with the help of these process-based simulation models, and can be weighed against other investments. Likewise, management options such as earlier planting and the use of longer duration varieties can be evaluated.

\section{Case III. Agroecological zonation studies}

A common methodology for agroecological zonation and characterization studies was developed (Bouman 1994; Bouman et al. 1993a) and is now being applied at several centres participating in the network. The approach has developed from the recognition of common problems experienced by the different teams. Such problems stem, in part, from the fact that simulation models are often developed and validated at crop-field-season scale, while their regional application involves the use of less detailed data sets. The user is then faced with issues like parameter uncertainty, gaps in basic input data, and year to year variations in weather. The choices made in solving such problems may largely determine the outcome of such simulation studies. The following framework was accepted as a step towards minimizing the bias arising from these subjective choices.

First, the overall objective of the study is stated (e.g. optimizing rice cropping systems), which is then further refined in terms of specific objectives 
Table 2. Changes in total rice production predicted by the ORYZA1 model for each country and region, under three climate change scenarios. AEZ codes refer to agroecological zones. For other acronyms see text. (Source: Matthews et al. 1994)

\begin{tabular}{|c|c|c|c|c|c|c|c|c|}
\hline \multirow[b]{2}{*}{ Country } & \multirow[b]{2}{*}{ AEZ } & Current & \multicolumn{2}{|c|}{ GFDL } & \multicolumn{2}{|c|}{ GISS } & \multicolumn{2}{|c|}{ UKMO } \\
\hline & & '000t & \%change & '000t & \%change & $000 t$ & \%change & '000t \\
\hline Bangladesh & 3 & 27691 & 14.2 & 31621 & -5.0 & 26298 & -2.8 & 26919 \\
\hline \multirow[t]{4}{*}{ China } & 5 & 8854 & -7.4 & 8201 & 0.3 & 8881 & -25.2 & 6619 \\
\hline & 6 & 79872 & 0.8 & 80484 & -21.7 & 62514 & -19.5 & 64334 \\
\hline & 7 & 91828 & 5.8 & 97196 & 5.8 & 97135 & 3.1 & 94695 \\
\hline & 8 & 2361 & -6.4 & 2209 & -14.2 & 2026 & -27.6 & 1710 \\
\hline \multirow[t]{5}{*}{ India } & 1 & 32807 & 4.6 & 34305 & -10.8 & 29272 & -5.5 & 31017 \\
\hline & 2 & 49949 & 1.8 & 50849 & -2.9 & 48493 & -7.9 & 46002 \\
\hline & 5 & 227 & -7.4 & 210 & 0.3 & 228 & -25.2 & 170 \\
\hline & 6 & .26628 . & 5.4 & 28069 & 3.2 & 27480 & -1.3 & 26287 \\
\hline & 8 & 1011 & -6.4 & 946 & -14.2 & 867 & -27.6 & 732 \\
\hline Indonesia & 3 & 44726 & 23.3 & 55155 & 9.0 & 48748 & 5.9 & 47387 \\
\hline Japan & 8 & 12005 & -6.4 & 11231 & -14.2 & 10300 & -27.6 & 8696 \\
\hline Malaysia & 3 & 1744 & 24.6 & 2173 & 17.6 & 2050 & 26.8 & 2211 \\
\hline Myanmar & 2 & 13807 & 21.5 & 16776 & -10.5 & 12356 & 1.2 & 13974 \\
\hline Philippines & 3 & 9459 & 14.1 & 10797 & -11.8 & 8340 & -4.7 & 9018 \\
\hline South Korea & 6 & 8192 & -13.6 & 7078 & -5.3 & 7755 & -21.9 & 6401 \\
\hline Taiwan & 7 & 2798 & 11.8 & 3128 & 12.8 & 3156 & 28.0 & 3583 \\
\hline Thailand & 2 & 20177 & 9.3 & 22044 & -4.7 & 19230 & -0.9 & 19989 \\
\hline Total & & 434136 & & 462472 & & 415129 & & 409743 \\
\hline \%change & & & & 6.5 & & -4.4 & & -5.6 \\
\hline
\end{tabular}

that can be addressed with the help of simulation models, such as the quantification of potential yields, of actual yield gaps, of water requirements, of optimum planting times for given crops. As a next step, the appropriate model is selected, depending not only on objectives but also on the availability of input data. Along with the model, other tools can be selected such as a weather generator, a parameter distribution generator, and weather and soil data bases.

For each land unit, calculations for many years of weather data are made first, using single (e.g. mean) values for crop and soil parameters. The variation in predicted outputs quantifies the effect of weather variation. Depending on the importance of these effects, one may choose to define worst, best and average years, e.g. in terms of yield level. Subsequently, for each of these extreme cases, the analysis is repeated, now using probability distributions rather than single values to characterize crops and soils. This leads to prob- 
ability distributions of crop performance in the distinguished representative weather types. These are graphed as maps or tabulated, or they are used as a basis for further risk assessment studies. It is often useful to compare the results with the objectives specified at the outset of the study, and to collect further data where necessary, or to introduce adaptations in the model.

The software developed for this framework includes, apart from models for potential, water limited and nitrogen limited rice growth, also tools for weather generation (IMSP, SIMMETEO), for generation of parameter distributions (RIGAUS), a weather data system (WEATHER) and a user friendly shell (SARP-Shell). This shell facilitates the use of the above tools, the selection of input data sets and the linkage with models, the performance of reruns, and the analysis and presentation of outputs.

A number of zonation studies have been reported (Bouman et al. 1993b), with emphases on linkage with GIS (Wopereis et al. 1993; Pannangpetch 1993), uncertainty and risk analysis (Aggarwal 1991; Lansigan and Orno 1993), and economic analysis (Pan Jun 1994; Labios et al. 1994). An example is given in figure 4. In 1994-1995, SARP teams will proceed with the zonation work along these lines in India (TNRRI, CRRI), Indonesia (BORIF, SURIF), China (ZAU, CNRRI), The Philippines (PhilRice, UPLB) and Bangladesh (BRRI). Some of these groups will address more specifically yield potentials, yield gap analysis and annual yield variation at given sites; others will perform economic analysis, along the lines suggested by Pandey (1994).

\section{National training courses}

Since the aim of the project was to build capacity in systems approaches in the region, existing SARP teams and NARCs were encouraged to organize their own, national, training programs after the formal SARP training phase which ended in 1991. Given the strong demand by the participating countries for more training in this field, six such courses have now been successfully organized and conducted by SARP scientists at the NARCs in India (2), China (2), Indonesia, and The Philippines. A few more are in preparation. In all cases, most of the participants were from sister institutes of the organizing NARCs, in addition to direct colleagues of the organizing teams. SARP staff support to these courses consisted of guest lectures, documentation, software, and sometimes small financial support for local travel and accomodation. Several courses were completely independent of SARP staff and financial support. The course format was often a concise form of the SARP blueprint, including a case study and a final reporting workshop, covering potential and water limited production processes. Two specialized training courses were held by TNAU (India), one on nitrogen management, the other on water management in rice. 

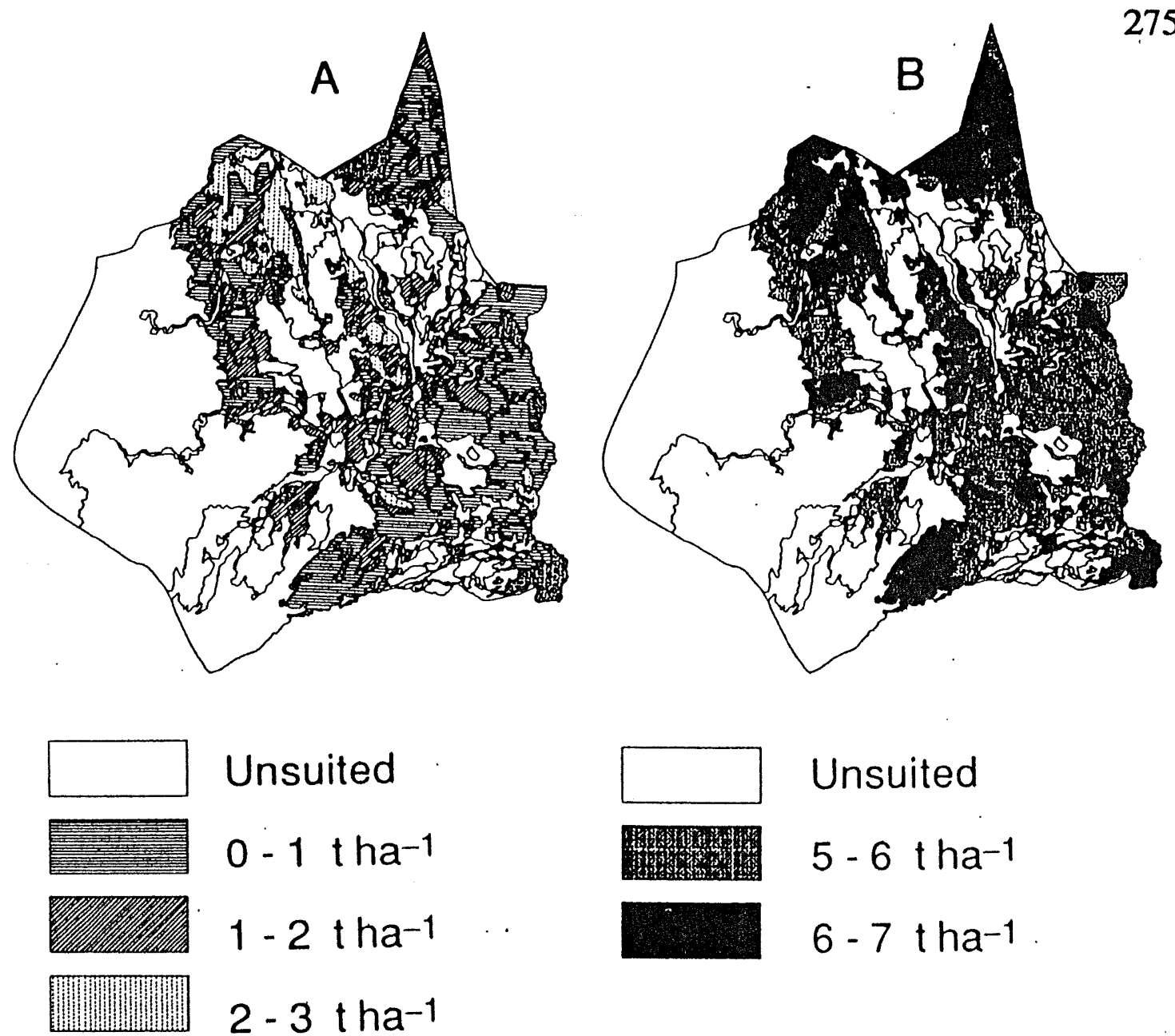

\section{Unsuited}

$0-1$ tha $^{-1}$

$1-2$ tha-1

2 - 3 tha-1

$$
5-6 \text { tha-1 }
$$

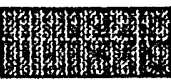

Fig. 4. Map of simulated rainfed rice yield $\left(\mathrm{tha}^{-1}\right)$ for Tarlac Province in The Philippines, at $10 \%$ (a) and $90 \%$ (b) cumulative probability. Simulations were based on observed soil hydraulic characteristics in the area, and on historic (5 years) and generated long-term (25 years) weather data. (Source: Wopereis et al. 1993)

\section{Fellowships}

The project provides fellowships to support long (1 year) and short ( 3 months) duration visits of network members to IRRI and AB-DLO/TPE-WAU. Visits with clearly defined goals - such as developing specific (sub)models, analyzing data sets, and finalizing workshop proceedings - are an effective mechanism for interaction and simultaneously serve the network as a whole via their outputs. To some extent these visits reduce the need for extended visits by SARP staff to teams, as conducted in the earlier project phases, although obviously only a limited number of participants can be addressed directly by this mechanism.

In addition to the above, SARP offers five $\mathrm{PhD}$ sandwich positions. A 'sandwich' consists of an initial visit (to AB-DLO/TPE-WAU or IRRI) fol- 
lowed by field research at the home institute, again followed by a final phase in Wageningen during which the thesis is completed and presented. These fellowships were introduced to create opportunities for network members while avoiding the long term absence from the home institute usually associated with $\mathrm{PhD}$ programs. In this respect the mechanism works well; another advantage is that certain topics can be developed 'in depth', which would otherwise leave gaps. In terms of absolute numbers, the contribution of the 'PhD fellowships mechanism' to reinforcement of the research network is limited. Its main overall contribution lies in the improvement of insights and models, made available to other network participants.

\section{SARP Research Proceedings}

A series of publications was initiated for team members and SARP staff to publish and report developments in modelling and experimental work related to model development. Issues often take the shape of workshop proceedings. They may also be devoted entirely to a particular model or group of modules, or may compile the results of network-wide experiments. It is anticipated that $10-15$ issues will be completed by the end of 1995 . The currently available titles are listed in Appendix 1. The issues are officially registered and are sent to all 'rice libraries'. The presented papers may serve to encourage more formal, internationally refereed publications.

\section{Transfer of coordination and network continuity}

The research coordination (see section 'Key elements of the Application Phase') was, upto 1994, in the hands of full time SARP staff members. During the last two project years (1994-1995), coordination activities are transferred to four members of the participating NARCs. They were assigned by the SARP Steering Committee, a group of NARCs' research leaders.

The formal and logistic aspects of these assignments are complex. On the one hand a long term commitment of NARCs to research coordination is sought; on the other hand the capacity per centre is narrow (single individuals) and the time frame covered by granted funding is short (two years). The issue is further complicated by the recognition that international coordination is less effective if actuated from a national platform. The consequence of taking an international centre (IRRI) as a basis (as in SARP) precludes, however, the development of a stronger institutional commitment of NARCs to internationall network coordination.

Reducing the international coherence for the benefit of more regional or national 'sub-networks' would seem a valid option, and could be effectuated via national training programs. This approach could meet with new difficulties, including those associated with the acceptance of leadership roles. The necessarily smaller pool of scientific expertise might also be insufficient to 
effectively energize a network in the long term. For the near future, SARP chose for theme oriented coordination by scientists from NARCs, based at IRRI and supported through 'visiting scientist' fellowships.

\section{Implications for NARCs}

In most of the NARCs, teams work effectively across the disciplinary department boundaries. Instrumentation is shared, and often members from different departments join in common experimental work. Team supervisors play a very important role here. In groups lacking an active and involved supervisor, a senior team member can sometimes enhance the interaction among team members. It appeared easier to develop interdisciplinary work involving agronomy, soil science, crop physiology and plant breeding than to involve entomologists and phytopathologists. One of the reasons may be that these disciplines are traditionally more focused on the biology of the plague organisms than on their interaction with the crop and that, as a consequence, field experimentation is organized differently.

The shift from traditional empirical work towards the investigation of causal relations, as implied by the systems approach, brings about some operational changes at the institutes. In the long run, research output generated via a systems approach has more general validity than purely empirical work, thus allowing broader extrapolation to other conditions (weather, season, soil type, cultivars, crops). Such an approach is therefore more cost effective. Within a short time frame, however, experimentation with a systems view requires more time input by scientists and by field and laboratory staff. In addition, the costs of individual experiments may increase, due to the costs of extra chemical analyses of plant and soil samples, as more in-depth analysis is often required. This is felt as a serious drawback, the more so because SARP provides virtually no financial support to cover these expenses.

The absence of direct operational financial support was part of the project philosophy. It seems now, however, that the advantages of this approach (no funding-induced deviation from the institute's identified research priorities) are outweighed by the disadvantages: assignment of capable staff to other (paying) projects; and insufficient access to experimental facilities, including support staff to assist in field and analytical work. Various SARP teams have drawn attention to these limitations during the more recent years. Core funding at many of the centres is probably insufficient to sustain the specific operational expenses of systems research for any prolonged period without outside support. Team members are creative and go to great lengths in solving such difficulties internally, but the sustainability of this format is at least questionable.

Modelling activities are sometimes not very accessible to those not skilled in computer use. Frequent participation, by the same individuals, in overseas workshops may also generate an imbalance among scientific staff. Some of 
the centres expanded their teams in response to such inequities, thus exposing other scientists to the new methodologies. This has not always proved effective from a scientific viewpoint, because new members often lack a basis in modelling.

Other teams have successfully organized their own training programs in order to extend the number of colleagues acquainted with systems approaches (see section 'National training courses'). SARP organized a short course in modelling for new members of exisiting teams in 1994. Other attempts to reinforce existing teams include the development and distribution of selfinstructive courseware and user-friendly software, to facilititate the operation of models (see section 'Software developments'). It appears that the selfinstructive courseware, in the currently available form, requires hands-on support to fully express its potential.

As in Europe, there is a strong tendency also in Asia for research centres to organize their research in programs and projects which are to be acquired in internal (national) competition. Several SARP teams have been successful in obtaining such grants (e.g. in India and Indonesia).

\section{Software developments}

SARP's main aim being the transfer of systems research skills, emphasis has been on the underlying principles of modelling and systems analysis, rather than propagating particular ready-made models. After all, each real world problem requires its own approach, and claims of universal models are generally illusive. Nevertheless, a demand for user-friendly ready-made models has developed for two reasons. One is the desire of many institutes to involve more novice team members without guiding them through lengthy training courses; the other is the $s$ demand for models that execute specific tasks, e.g. optimization of management, agro-ecological zonation, and exploration studies. To execute these tasks, models are conveniently run under a user friendly 'shell structure', which was developed to facilitate selection of models and model options, selection of input data sets, and the editing of data files. Examples of 'shell' applications in the SARP context are zonation studies for potential and water limited production, with smooth execution of multiple runs; various sensitivity analyses; and optimization of nitrogen use (see sections 'Cases I-III').

The introduction of user interfaces in turn sets its own demands of standardization of models and data formats. This curtails users' initiatives to 'play' with the model source codes. The dilemma between 'models easy to run' and 'models easy to adapt' reflects the existence of different user groups: those who wish to apply models in straightforward analyses, and those more involved with testing of hypotheses and model development. The solution chosen by SARP is to maintain two 'tracks', one being the free development of 'easy to change' models in a real simulation language (FST), offering 
programming versatility after only little initial training, the other being the development of more formalized model codes in FSE standard FORTRAN for running under the user interface. FSE (FORTRAN Simulation Environment; Van Kraalingen 1991) is a design structure for dynamic models. FST (FORTRAN Simulation Translator; Van Kraalingen et al. 1994) converts an FST model code into FSE; this translator has replaced the earlier used PCSMP language. Although FSE models still require slight adaptations before they can be run under the user interface, this two-track approach offers sufficient continuity from 'model development' to 'model application' to serve various user groups.

One principle maintained throughout these developments is that all models and modules are fully documented, both in terms of their scientific contents and their technical form, and that all source codes are available to all users.

\section{Conclusions}

Systems research networks such as SARP are useful to establish a common basis of concepts and models, and to design experiments to improve, validate and parameterize models for various applications. The latter include local in-depth studies on production constraints, but also eco-region-wide analyses for increased research efficiency and more adequate research prioritization. Both types of applications benefit from the specialist expertise mobilized through a network format, if combined with on-site interdisciplinary team approaches. The varieiety of environmental conditions and germplasm covered by a sufficiently widespread network allows the rigorous testing and adaptation of systems tools, including models, before their application. We believe that this should drastically improve the predictive capacity of models. For eco-regional analysis, i.e. the characterization of production systems and production conditions across eco-regions, and their expected responses to proposed changes, models are combined with data bases. The development of these along universal lines, in association with certain modelling standards, requires further attention in the near future. Agricultural research world-wide will benefit from attempts to standardize models and data formats.

Establishing systems research networks requires a long term investment in training, coordination and support. It involved, in the case of SARP, six years of formal training programs, followed by a joint research phase on applied topics. Frequent team visits by research coordinators, exchange fellowships, thematic workshops, joint research planning and a collective 'research proceedings' series all proved useful mechanisms for strengthening research capacity in the network. Simultaneously, these elements allowed the development of a common knowledge base expressed in validated models, quantified parameters, and research reports. 


\section{Appendix 1. SARP Research Proceedings}

Current (January 1995) titles available in the SARP Research Proceedings series.

\begin{tabular}{|c|c|c|}
\hline Title & Topic & Description \\
\hline $\begin{array}{l}\text { The SARP-project. Phase III (1992-1995). } \\
\text { Overviews, Goals, Plans. }\end{array}$ & $\begin{array}{l}\text { Project overview Sys- } \\
\text { tems Analysis }\end{array}$ & $\begin{array}{l}\text { Workshop } \\
\text { proceedings }\end{array}$ \\
\hline Agro-ecology of rice-based cropping systems. & Agro-ecology & $\begin{array}{l}\text { Workshop } \\
\text { proceedings }\end{array}$ \\
\hline $\begin{array}{l}\text { Mechanisms of damage by stem borer, bacterial } \\
\text { leaf blight and sheath blight and their effects on } \\
\text { rice yield. }\end{array}$ & Crop protection & $\begin{array}{l}\text { Workshop } \\
\text { proceedings }\end{array}$ \\
\hline $\begin{array}{l}\text { Nitrogen economy of irrigated rice: field and } \\
\text { simulation study. }\end{array}$ & Rice nitrogen & $\begin{array}{l}\text { Workshop } \\
\text { proceedings }\end{array}$ \\
\hline $\begin{array}{l}\text { ORYZA1 An Ecophysiological model for irri- } \\
\text { gated rice production. }\end{array}$ & ORYZA1 & $\begin{array}{l}\text { Model } \\
\text { documentation }\end{array}$ \\
\hline $\begin{array}{l}\text { The development, testing and application of } \\
\text { crop models simulating the potential production } \\
\text { of rice. }\end{array}$ & Potential production & $\begin{array}{l}\text { Workshop } \\
\text { proceedings }\end{array}$ \\
\hline $\begin{array}{l}\text { Analysis of damage mechanisms by pests and } \\
\text { diseases and their effects on rice yield. }\end{array}$ & $\begin{array}{l}\text { Pest and disease } \\
\text { management }\end{array}$ & $\begin{array}{l}\text { Workshop pro- } \\
\text { ceedings; } \\
\text { Methodology }\end{array}$ \\
\hline $\begin{array}{l}\text { The use of crop growth models in agro-eco- } \\
\text { logical zonation of rice. }\end{array}$ & Zonation & Methodogy \\
\hline $\begin{array}{l}\text { Agro-ecological zonation, characterization and } \\
\text { optimization of rice-based cropping systems }\end{array}$ & Agro-ecology & $\begin{array}{l}\text { Workshop } \\
\text { proceedings }\end{array}$ \\
\hline $\begin{array}{l}\text { ORYZA simulation modules for potential and } \\
\text { nitrogen limited rice production. }\end{array}$ & ORYZA modules & $\begin{array}{l}\text { Model } \\
\text { documentation }\end{array}$ \\
\hline
\end{tabular}

\section{Acronyms}

$\begin{array}{ll}\text { AB-DLO } & \begin{array}{l}\text { Research Institute for Agrobiology and Soil Fertility (Wageningen, } \\ \text { The Netherlands) } \\ \text { Bogor Research Institute for Food Crops, Central Research } \\ \text { Institute for Food Crops (Bogor, Indonesia) } \\ \text { BORIF-CRIFC } \\ \text { BRRI }\end{array} \\ \begin{array}{l}\text { Cropladesh Rice Research Institute (Joydebpur, Bangladesh) } \\ \text { CES }\end{array} & \begin{array}{l}\text { China National Rice Research Institute (Hangzhou, China) } \\ \text { CNRRI }\end{array} \\ \text { CRRI } & \begin{array}{l}\text { Central Rice Research Institute (Cuttack, India) } \\ \text { Directoraat Generaal voor Internationale Samenwerking (Directorate }\end{array} \\ \text { DGIS } & \begin{array}{l}\text { General for International Cooperation) } \\ \text { Dienst Landbouwkundig Onderzoek (Agricultural Research }\end{array} \\ \text { DLO } & \begin{array}{l}\text { Department) } \\ \text { Environmental Protection Agency }\end{array} \\ \text { EPA } & \text { FORTRAN Simulation Environment } \\ \text { FSE } & \text { FORTRAN Simulation Translator } \\ \text { FST } & \end{array}$




\begin{tabular}{|c|c|}
\hline GIS & Geographic Information System \\
\hline IARI & Indian Agricultural Research Institute (New Delhi, India) \\
\hline IESAM-UPLB & $\begin{array}{l}\text { Institute for Environmental Studies and Management, University } \\
\text { of the Philippines (Los Banos, Philippines) }\end{array}$ \\
\hline IRRI & International Rice Research Institute (Los Banos, Philippines) \\
\hline JAU & Jiangxi Agricultural University (Nanchang, China) \\
\hline KKU & Khon Kaen University (Khon Kaen, Thailand) \\
\hline MARDI & $\begin{array}{l}\text { Malaysian Agricultural Research and Development Institute (Serdang, } \\
\text { Malaysia) }\end{array}$ \\
\hline NARC & National Agricultural Research Center \\
\hline PUAT & ar University of Agriculture and Technology (Pantnagar, Indi \\
\hline SARP & Simulation and systems Analysis for Rice Production \\
\hline SURIF-CRIFC & $\begin{array}{l}\text { Sukamandi Research Institute for Food Crops, Central Research } \\
\text { Institute for Food Crops (Sukamandi, Indonesia) }\end{array}$ \\
\hline TNAU-SWMRI & $\begin{array}{l}\text { Tamil Nadu Agricultural University, Soil and Water Management } \\
\text { Research Institute (Thanjavur, India) }\end{array}$ \\
\hline TNAU-TNRRI & $\begin{array}{l}\text { Tamil Nadu Agricultural University - Tamil Nadu Rice Research } \\
\text { Institute (Aduthurai, India) }\end{array}$ \\
\hline TNAU-WTC & $\begin{array}{l}\text { Tamil Nadu Agricultural University - Water Technology Center } \\
\text { (Coimbatore, India) }\end{array}$ \\
\hline TPE & Department of Theoretical Production Ecology, WAU \\
\hline UPM & Universiti Pertanian Malaysia (Serdang, Malaysia) \\
\hline WAU & Wageningen Agricultural University (Wageningen, The Netherlands) \\
\hline ZAU & Zhejiang Agricultural University (Hangzhou, China) \\
\hline
\end{tabular}

\section{References}

Aggarwal P K (1991) Estimation of the optimal duration of wheat crops in rice-wheat cropping systems by crop growth simulation. Pages 3-10 in Penning de Vries F W T, Van Laar H $\mathrm{H}$, Kropff M J (Eds.) Simulation and systems analysis for rice production (SARP). Pudoc, Wageningen, The Netherlands. ISBN 90-220-1059-7.

Ten Berge H F M (1993) Building capacity for systems research at national agricultural research centres: SARP's experience. Pages 515-538 in Penning de Vries F W T, Teng P S, Metselaar K (Eds.) Systems Approaches for Agricultural Development. Kluwer Academic Publishers, Dordrecht, The Netherlands.

Ten Berge H F M, Wopereis M C S, Shin J C (Eds.) (1994) Nitrogen economy of irrigated rice: field and simulation studies. SARP Research Proceedings, AB-DLO, Wageningen, The Netherlands. ISBN 90-73384-22-2.

Bouman B A M, Penning de Vries F W T, Riethoven J J M, Kropff M J, Wopereis M C S (1993a) Application of simulation and systems analysis in rice cropping optimization. Pages 1-15 in Bouman B A M, Van Laar H H, Wang Zhaoqian (Eds.) Agroecology of rice based cropping systems. SARP Research Proceedings, AB-DLO, Wageningen, The Netherlands. ISBN 90-73384-18-4.

Bouman B A M, Van Laar H H, Wang Zhaoqian (Eds.) (1993b) Agroecology of rice based cropping systems. SARP Research Proceedings. AB-DLO, Wageningen, The Netherlands. ISBN 90-73384-18-4.

Bouman B A M (1994) A framework to deal with uncertainty in soil and management parameters in crop yield simulation; a case study for rice. Agricultural Systems 46:1-17.

Van Kraalingen D W G (1991) The FSE system for crop simulation. Simulation Report CABO-TT nr 23. CABO-DLO, Wageningen, The Netherlands. 
Van Kraalingen D W G, Rappoldt C, Van Laar H H (1994) The FORTRAN Simulation Translator (FST), a simulation language. Pages 219-230 in Goudriaan J, Van Laar H H (Eds.) Modelling crop growth processes. Kluwer Academic Publishers, Dordrecht, The Netherlands.

Kropff M J, Penning de Vries F W T, Teng P S (1994) Capacity building and human resource development for applying systems analysis in rice research. Pages 323-339 in Goldsworthy P, Penning de Vries F W T (Eds.) Opportunities, use and transfer of systems research methods in agriculture to developing countries. Kluwer Academic Publishers, Dordrecht, The Netherlands.

Labios R V, Delos Santos R E, Salazar A M, Villancio V T (1994) Rice-upland crop rotations in rainfed lowland rice areas in Bulacan, Philippines. In Lansigan F P, Bouman B A M, Van Laar H H (Eds.) Agro-ecological zonation, characterization and optimization of rice-based cropping systems. SARP Research Proceedings. AB-DLO, Wageningen, The Netherlands (in prep.).

Lansigan F P, Orno J L (1993) Simulation analysis of risk and uncertainty in crop yield due to climatic variations and change. Pages 115-125 in Bouman B A M, Van Laar H $\mathrm{H}$, Wang Zhaoqian (Eds.) Agroecology of rice based cropping systems. SARP Research Proceedings. AB-DLO, Wageningen, The Netherlands. ISBN 90-73384-18-4.

Matthews R B, Kropff M J, Bachelet D, Van Laar H H (Eds.) (1994) The impact of global climate change on rice production in Asia: a simulation study (in press).

Pan Jun (1994) Systems analysis and simulation applied to the 'Central China Double and Single Rice Cropping Region'. In Lansigan F P, Bouman B A M, Van Laar H H (Eds.) Agroecological zonation, characterization and optimization of rice-based cropping systems. SARP Research Proceedings. AB-DLO, Wageningen, The Netherlands (in prep.).

Pandey S (1994) Risk analysis and crop growth modelling. In Lansigan F P, Bouman B A M, Van Laar H H (Eds.) Agro-ecological zonation, characterization and optimization of rice-based cropping systems. SARP Research Proceedings. AB-DLO, Wageningen, The Netherlands (in prep.).

Pannangpetch K (1993) Application of model simulation to evaluate rice production at the district level. Pages 16-26 in Bouman B A M, Van Laar H H, Wang Zhaoqian (Eds.) Agroecology of rice based cropping systems. SARP Research Proceedings, AB-DLO, Wageningen, The Netherlands. ISBN 90-73384-18-4.

Wopereis M C S, Kropff M J, Hunt E D, Sanidad W, Bouma J (1993) Case study on regional application of crop growth simulation models to predict rainfed rice yields: Tarlac Province, Philippines. Pages 27-46 in Bouman B A M, Van Laar H H, Wang Zhaoqian (Eds.) Agroecology of rice based cropping systems. SARP Research Proceedings, AB-DLO, Wageningen, The Netherlands. ISBN 90-73384-18-4. 